\title{
Patients as strategic partners in hospital settings: Trust, participation, relational value, and loyalty
}

\author{
Kwaku Ahenkora*1, Ernestina Armah ${ }^{2}$, Frederick Santuoh ${ }^{2}$, Theresa Sarpong ${ }^{3}$, Confidence Atakro ${ }^{2}$ \\ ${ }^{1}$ Christ Apostolic University College, Kumasi, Ghana \\ ${ }^{2}$ Christian Service University College, Kumasi, Ghana \\ ${ }^{3}$ Nursing and Midwifery Training School, KATH, Kumasi, Ghana
}

Received: May 27, 2019

DOI: $10.5430 /$ jha.v8n5p1
Accepted: July 1, 2019

Online Published: July 30, 2019

\begin{abstract}
Objective: The need to motivate patients to participate as strategic partners in healthcare exists, and this has prompted the development of relational models of value creation. This study assesses the effect of trust-in doctor/nurse on patient participation as well as the outcomes on perceived relational value and loyalty.

Methods: An empirical model from the patient's point of view was designed and tested. Data were collected from 209 patients, who had attended public (10) and private (10) hospitals/clinics, and analyzed using the principles of structural equation modelling. Results: The results show that patients' perception of trust-in-doctor/nurse is an antecedent of patient participation. Patient participation has positive effects on perceived patient relational value, and this subsequently affects patient satisfaction, affective commitment, and loyalty.

Conclusions: The study shows that trust affects patient participation behaviour, and the outcome of this behaviour contributes to value creation and loyalty in service delivery.

Managerial implication: Nurses and doctors who build trust and involve patients create relational value with them, which enable patients to experience satisfaction and commitment, and this leads to long term relationships with the hospital. The study indicates that building trust and promoting patient participation should be a strategic imperative for management.
\end{abstract}

Key Words: Trust, Patient participation, Relational value, Satisfaction, Strategic partners, Loyalty

\section{INTRODUCTION}

Patient-centred care is of extreme importance in today's health care delivery, and increasingly, hospitals around the world are adopting it. Patients exercise their healthcare rights when they participate in healthcare services that regard patient rights as partners in decision making. ${ }^{[1,2]}$ Patient participation is involving, and there is the continual need to understand the value it creates to enhance its promotion in hospitals. ${ }^{[3]}$ Customers act as participants and play vital roles in the service delivery process. ${ }^{[4,5]}$ In the service industry, studies suggest the need to increase opportunities for co-production between service providers and their customers as customer participation is a source of competitive advantage and various positive outcomes for both customers and service providers. ${ }^{[4,6]}$ Customers participate actively in the service transaction by supplying "activities" and "input" (information and efforts), and not as mere spectators. ${ }^{[7]} \mathrm{Ser}-$ vice providers are, therefore, required to collaborate with customers in value co-creation-to create values that meet mutual needs. ${ }^{[8]}$ Value co-creation is of utmost importance for health service professionals whose services require high contact and credence. ${ }^{[6]}$

*Correspondence: Kwaku Ahenkora; Email: k.ahenkora@yahoo.co.uk; Address: PO Box 6745, Kumasi, Ghana. 
Patients are essential resources for co-creating value in sustainable healthcare. ${ }^{[9]}$ There are indications of progress in patient participation in recent years; from subjects who passively receive instruction and treatment from professionals to service supporters who search for information and manage their health. ${ }^{[10]}$ Such participation leads to improved service quality and better service control for customers, and service providers also gain from increased customer satisfaction and productivity. ${ }^{[5]}$ Customer participation affects service quality, as participating customers are known to derive more satisfaction than non-participating customers from better service outcomes. ${ }^{[11,12]}$ Customer feedback is highly dependent on a good relationship with the provider in service contexts where participation is expected, thus emphasizing the importance of understanding the effects of the predictors of relational qualities such as trust on customer participation behaviour. ${ }^{[12]}$

Patient participation is needful, but the degree and quality of patient inputs can vary considerably. Patient empowerment, shared decision making and self-management are different aspects of participation. ${ }^{[13,14]}$

The patient-professional relational approach is a means of enhancing value creation, and previous studies have provided different pathways to value creation and the outcomes. Patient empowerment impacts value co-creation, and the antecedents of empowerment include patient participation, while those of value co-creation include patient participation and patient citizenship behaviours. ${ }^{[15]}$ Trust-in personnel is known to influence participation (co-delivery and value co-design behaviours), which subsequently affects customer perceived value and loyalty. ${ }^{[16]}$ This study, however, did not consider the roles of satisfaction and affective commitment. Chen and Chen modelled the path from customer participation to relational value, satisfaction, and repurchase intentions, and suggested the need to understand the role of trust in future models. ${ }^{[6]}$ The study fills this gap and aptly assesses trust as an antecedent of patient participation behaviour as well as the outcomes; patient perceived relational value, satisfaction, affective commitment and loyalty.

\subsection{Theoretical background and hypothesis}

This section provides the theoretical basis for the conceptual model of patient perception on the relationships among trust in doctors and nurses as service personnel, patient participation, patient relational value, affective commitment, satisfaction and loyalty.

\subsubsection{Patient trust-in-doctor/nurse}

Trust is a fundamental requirement for quality human interaction and exchange. Consumers associate trust with providers whose service personnel are honest, reliable, and supportive, and therefore feel confident and comfortable to provide information, suggestions and their expectations for the service task to be performed. ${ }^{[16]}$ Trust-in-personnel in dyadic relationships is a customer's willingness to depend on a frontline service personnel's promise and be vulnerable to the actions of this personnel who shows appropriate integrity, benevolence, and ability, and that the outcome of such actions could be predicted. ${ }^{[16,17]}$ In this regard, a customer who trusts the service personnel becomes vulnerable but demonstrates cooperative behaviour in routine service tasks, such as making preferences known and providing information; or would make contributions to value co-creation by making suggestions to the design of personalised product or services. ${ }^{[8,11]}$ Similarly, in health care delivery, trust-in-doctor/nurse connotes the extent to which the patient feels the doctor/nurse is dependable, honest, competent and responsive.

\subsubsection{Patient participation}

Active participation in healthcare is being promoted as it can contribute to patients' healthcare quality and safety. ${ }^{[18]}$ In medical treatments, patients may either contribute physical labour for the doctor or nurse to deliver a service or provide information that can help create, design or plan a service. ${ }^{[19]}$ Attempts at developing and validating the $4 \mathrm{P}$ patient participation tool, which should enable patients to prioritize and evaluate their participation in healthcare, identified items corresponding to "having a dialogue", "sharing knowledge", "planning" and "managing self-care". ${ }^{[20]}$ Understanding participation from the patient's point of view is useful, as patients and health professionals are known to differ in their views on the concept of participation. ${ }^{[20,21]}$ It has been observed that patients' definition of participation goes beyond decision making, as was held by healthcare staff, to include comprehension, mutual communication, having and applying knowledge, and being confident, thereby prompting the need to promote the patient's view of participation in health care. ${ }^{[20]}$ This study considers patient participation as a behavioural construct and conceptualizes it as the degree to which patients provide and receive information, take part in decision making concerning care and treatment planning, and the level of participation in the service delivery and the relational value process. Consistent with trust in dyadic relationships, the trust displayed by the doctor or nurse is a prerequisite for meaningful patient participation in the service delivery process.

H1: Patients' perception of trust-in-doctor/nurse will positively impact their perception of patient participation

ISSN 1927-6990 E-ISSN 1927-7008 


\subsubsection{Patient relational value}

The service-dominant logic argues that "value can only be created with and determined by the user" and this makes service delivery and value co-creation relational. ${ }^{[8]}$ The perceived value of customer participation varies but includes, among others, customized service and greater control, and participation enjoyment. ${ }^{[5,22]}$ Customer participation is known to positively affect customer relational value or the co-creation of value. ${ }^{[15,16]}$ Consistent with the customer service literature, patient relational value is the value derived from the bonds between the patient and doctor/nurse, and posit a positive association between patient participation and relational value.

H2: Patients' perception of patient participation will positively impact their perception of patient relational value.

\subsubsection{Patient satisfaction}

The concept of satisfaction has received much attention in the service literature, and satisfaction surveys are now familiar in most organizations. Customers experience satisfaction, expressed as feelings of pleasure when the perceived performance of service exceeds their expectations. ${ }^{[23]}$ Customer satisfaction can be transaction-specific or cumulative, and it is also the basis of comparing the service performance of different providers. ${ }^{[24]}$ The relationship marketing literature provides ample evidence of the positive effect customer relational value has on satisfaction, especially in service situations like health care where building relationship and credence are essential. ${ }^{[6,25]}$ Patient satisfaction is a core outcome measure for measuring and evaluating healthcare service provision. ${ }^{[26]}$ The quality of the therapeutic alliance that exists between patient and provider affects general satisfaction. ${ }^{[27]}$ Thus:

H3: Patients' perception of patient relational value will positively impact their perception of patient satisfaction.

\subsubsection{Patient affective commitment}

There are different views on the extent to which customer participation affects affective commitment, as there exist both positive significant and insignificant relationships. ${ }^{[6,12,28]} \mathrm{A}$ positive relationship indicates that customers who experience relational value with employees tend to be more involved with the company (i.e. affective commitment). Excellent customer service is associated with friendly and interpersonal relationships between customers and staff. ${ }^{[29]}$ The notion of person-centred care requires health professionals to create conditions for mutual respect, the exercise of individual rights and self-determination, and participation as shared aims and collaboration. ${ }^{[30]}$ Patient-centred care would make the service relationship enjoyable and facilitate bonding. Affective commitment, from the patient participation perspec- tive, can be defined in terms of how the patient feels about the health service and the extent to which the patient subsequently bonds psychologically with the provider. Consistent with results from the service literature, an enhanced relationship between the patient and the health service provider should lead to the patient bonding better.

Thus it is proposed:

H4: Patients' perception of patient relational value will positively impact their perception of affective commitment.

The goals of patient participation are to promote patient rights, quality care and service delivery. The patient and nurse/doctor relationship is a collaborative one for sharing knowledge, decision making and promotion of selfmanagement. Health care delivery is a high contact service where doctors, nurses and other support staff provide service to patients, and particularly for nurses, they spend more contact hours with patients and their families. ${ }^{[31]}$ Nurses and support staff are, therefore, the most critical determinant of perceived service quality and patient satisfaction. ${ }^{[32]}$ Customers who have decision power derive satisfaction from the service delivery process, and satisfaction is an essential antecedent of affective commitment in different service contexts. $^{[32,33]}$ For the patient participation context, it is expected that:

H5: Patients' perception of satisfaction will positively impact their perception of affective commitment.

\subsubsection{Patient loyalty}

Customer loyalty is associated with the value derived from high-quality services and satisfying experiences. Customer loyalty is conceptualized as an attitude or behaviour. Attitudinal loyalty relates to the pleasant disposition that customers have towards one service over another, but they may switch to an alternative provider with better attribute and price. Behavioural loyalty, however, is a commitment to a service or brand despite the availability of competitive alternatives. ${ }^{[34]}$ Given the local context of healthcare service provision, it is prudent to adopt a working definition of loyalty as a combination of patients' attitude and behaviour that translates into repurchase or regular use of service. Dong et al. concluded that customer participation is positively related to service quality and satisfaction but has mixed impacts on future purchase intentions. ${ }^{[12]}$ Satisfaction is a prerequisite for loyalty as satisfied customers are less likely to yield to alternative offers from competitors, tend to choose the same service providers, and are likely to recommend the service to others. ${ }^{[35]}$ Patients who are continually satisfied with the services provided by their doctor/nurse are likely to stay with the facility, speak well of the personnel and recommend them 
to others. This study suggests that patient satisfaction will affect loyalty, and proposes that:

H6: Patients' perception of satisfaction has a positive impact on their perception of patient loyalty.

Service users with a high sense of affective commitment have emotional bonds, tend to stick with providers and display loyalty behaviours such as repurchase intention. ${ }^{[6,36]}$ In healthcare service provision, patients are likely to translate bonding with the doctor/nurse into loyalty and a readiness to come back to the facility. Guided by previous works, the study posits that:

H7: Affective commitment associates positively with patient loyalty.

Figure 1 shows the conceptual framework and the seven hypotheses.

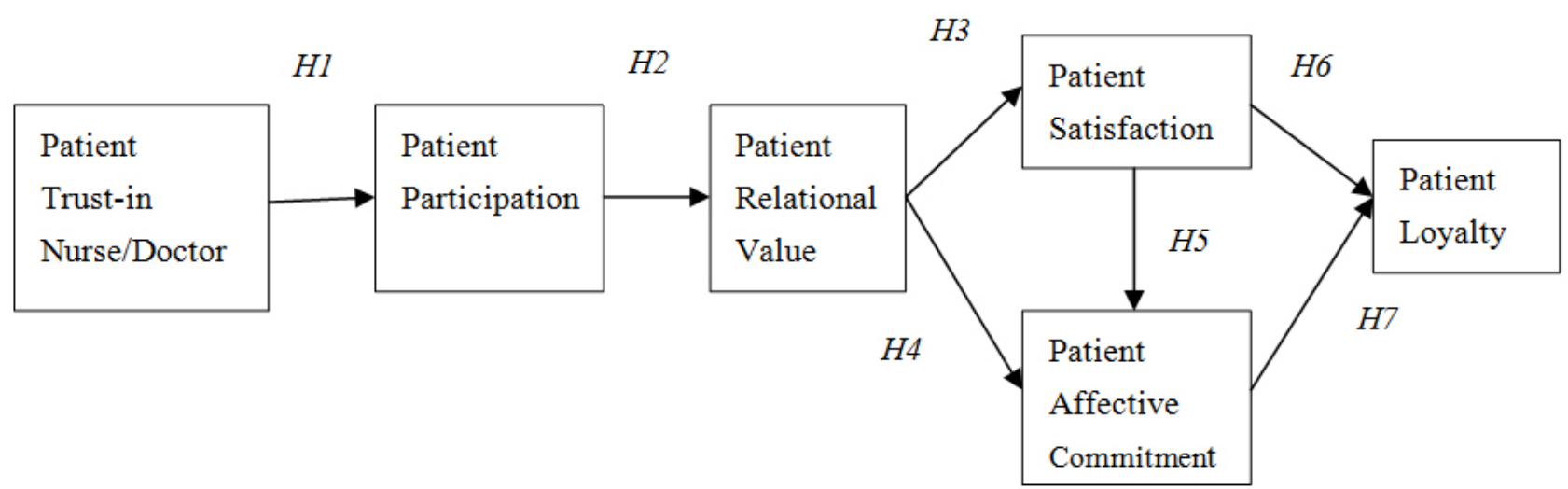

Figure 1. Conceptual framework

\section{MethodS}

\subsection{Measures}

The study adopted previous scales with slight wording modifications to fit the health service contexts. The constructs were assessed using a five-point Likert-type scale. The anchors ranged from strongly disagree (1), neither agree nor disagree (3), to strongly agree (5). Perceived trust in frontline personnel (doctors and nurses) was measured with scales developed by Sirdeshmukh et al., ${ }^{[17]}$ and validated by Li et al. ${ }^{[16]}$ Patient participation looked at the extent to which patients participated in the health service delivery process based on their encounter with frontline personnel (doctors and nurses). It was measured with items adapted from previous scales, but tailored to patients' preferences on patient participation. ${ }^{[5,17,23]}$ The scale of perceived patient relational value was based on Li et al., ${ }^{[16]}$ and Cheng and Chen. ${ }^{[6]}$ The items measured enjoyable interaction and relational approval from doctors and nurses. Patients' satisfaction with the services provided by doctors and nurses were measured with items from Lam et al. ${ }^{[37]}$ and Chen and Chen. ${ }^{[6]}$ Affective commitment was measured with items validated by Chen and Chen. ${ }^{[6]}$ Behavioural loyalty was measured with items validated by $\mathrm{Li}$ et al. ${ }^{[16]}$ Single-item questions were used to obtain data on health facility attended, gender, age and employment status.

\subsection{Data collection and sample}

The staff and students of the Christian Service University College were informed of the study and requested to participate in a survey in January in 2018. Two hundred and twenty participants were systematically and randomly selected out of three hundred and thirty who self-enlisted. Two hundred and nine usable questionnaires were used in the data analysis. The sample size is adequate as a sample size of 200 cases is useful for structural equation modelling. ${ }^{[38]}$ The questionnaire required participants to indicate the last time they visited the hospital/clinic and interacted with the nurse and doctor who examined them. The characteristics of the sample are shown in Table 1.

\subsection{Data analysis technique}

The data were analysed using the principles of structural equation modelling, sem (STATA). The recommended twostage procedure of establishing a congruent measurement model, and then testing the hypothesis by analysing the structural model was used. ${ }^{[39]}$ Given that scales were adopted from previous studies, confirmatory assessments of dimensionality, convergent validity, reliability, and discriminant validity were undertaken. 
Table 1. Characteristics of the sample

\begin{tabular}{ll}
\hline Variable & $\mathbf{n}(\boldsymbol{\%})$ \\
\hline Gender & $87(41.6)$ \\
$\quad$ Male & $122(58.4)$ \\
$\quad$ Female & \\
Age & $105(50.23)$ \\
18-24 & $64(30.62)$ \\
25-34 & $25(11.96)$ \\
35-44 & $10(4.78)$ \\
45-54 & $5(2.39)$ \\
$>$ 54 & \\
Work status & $105(50.3)$ \\
Staff of the University & $44(21.1)$ \\
Students in employment & $56(26.8)$ \\
Non-working Students & $109(52.1)$ \\
P-6 Mospital Attendance & \\
\hline P-3 Months & \\
\hline
\end{tabular}

\section{Results}

\subsection{The measurement model}

The reliability of each item of the scale of measure was assessed on the basis of standardized factor loadings $(>0.7),{ }^{[40]}$ Cronbach Alpha (>0.7), ${ }^{[41]}$ composite reliability of the constructs $(>0.7),{ }^{[41]}$ and average variance extracted $(>0.5) .{ }^{[42]}$ The ranges of the values of the standardized factor loadings (0.701-0.991), Cronbach Alpha (0.807-0.889), composite reliability $(0.836-0.889)$ and average variance extracted $(0.562-$ 0.718 ) for the scales, showed that the items and the scales satisfied the criteria (see Table 2). The results in Table 3 show that the criterion for discriminant validity was met as the square root of the AVE value of the individual construct is larger than its correlation with other constructs. ${ }^{[42]}$ The conditions for reliability, convergent and discriminant validities were met.

The fit statistics of the measurement model are within the generally accepted thresholds and suggest an acceptable goodness-of-fit (see Table 2). The Chi-square test is significant $\left(\chi^{2}=671.16, p \leq .001\right)$, and the ratio chi-square/degrees of freedom (3.0) is acceptable as a ratio in the range of 3-1 is indicative of an acceptable fit. ${ }^{[38]}$ The comparative fit index $(\mathrm{CFI}=0.93)$, the non-normed fit index $(\mathrm{TLI}=0.95)$, the root mean square error of approximation RMSEA $=0.07$ ), and the standardised root mean square residual (0.02) are indicative of a good fit. ${ }^{[39,43-46]}$

\subsection{The structural model and hypothesis testing}

The structural model was assessed by the goodness of fit indices and the hypotheses tested by examining the variance measured $\left(R^{2}\right)$ by the antecedent constructs, the significance of the path coefficients, and $t$-values. The results are shown in Table 4. Overall, the fit indices of the structural model were good, as shown by the values obtained: $\chi^{2}=671.16$ $(p<.001), \chi^{2} / \mathrm{df}=3.0, \mathrm{RMSEA}=0.07, \mathrm{CFI}=0.93$, TLI $=0.95, \mathrm{SRMR}=0.023$. The $\chi^{2} / \mathrm{df}$ value was equal to the threshold of $3,{ }^{[38]}$ the CFI was greater than the cutoff of $0.92,{ }^{[41]}$ the RMSEA was equal to the threshold value of 0.07 , and the SRMR was lower than this threshold value. ${ }^{[41]}$

The path coefficients in the model are all significant, supporting the hypotheses that: patients' perception of trust-indoctor/nurse positively impacts their perception of patient participation $(\beta=0.59, p<.001)$, patients' perception of participation affects their perception of patient relational value ( $\beta=0.91, p<.001)$, patients' perception of relational value impacts their perception of patient satisfaction $(\beta=0.64, p$ $<.001$ ), patients' perception of relational value affects their perception of affective commitment $(\beta=0.38, p<.001)$, patients' perception of the relational value affects their perception of satisfaction $(\beta=0.42, p<.001)$, perception of patient satisfaction positively affects perception of affective commitment $(\beta=0.42, p<.001)$, patients' perception of satisfaction has a positive impact on their perception of patient loyalty $(\beta=0.55, p<.001)$, and perception of affective commitment impacts patients' perception of loyalty $(\beta=$ $0.47, p<.001)$.

The model explained $60.6 \%$ of the variance in loyalty, $55.7 \%$ of the variance in affective commitment, $24.3 \%$ of the variance in patient satisfaction, $81.6 \%$ of the variance in patient relational value, and $39.5 \%$ of the variance in patient participation (see Figure 2). The results show that the explanatory power of the model is high. 
Table 2. The measurement model

\begin{tabular}{|c|c|c|c|}
\hline Construct & $\begin{array}{l}\text { Cron-bach's } \alpha \\
(>0.7)^{\mathrm{a}}\end{array}$ & $\begin{array}{l}\text { CR } \\
(>0.7)^{\mathrm{a}}\end{array}$ & $\begin{array}{l}\text { AVE } \\
(>0.5)^{a}\end{array}$ \\
\hline Patient Trust- in- Doctor/Nurse (PT) & 0.841 & 0.889 & 0.667 \\
\hline Patient participation (PP) & 0.807 & 0.836 & 0.562 \\
\hline Patient relational value (PRV) & 0.881 & 0.884 & 0.718 \\
\hline Patient satisfaction (PS) & 0.902 & 0.888 & 0.668 \\
\hline Patient Affective commitment (PAC) & 0.837 & 0.845 & 0.578 \\
\hline Patient Loyalty (PL) & 0.872 & 0.874 & 0.635 \\
\hline \multicolumn{2}{|l|}{ Items } & Factor Loading & $t$-value $(p<.05)$ \\
\hline \multicolumn{2}{|c|}{ PT1: I feel that the doctor/nurse who saw me is dependable } & 0.883 & 38.77 \\
\hline \multicolumn{2}{|c|}{ PT2: I feel that the doctor/nurse who saw me is competent } & 0.854 & 34.08 \\
\hline \multicolumn{2}{|c|}{ PT3: I feel that the doctor/nurse who saw me is of high Integrity } & 0.789 & 24.72 \\
\hline \multicolumn{2}{|c|}{ PT4: I feel that the doctor or nurse who saw me is responsive } & 0.733 & 19.22 \\
\hline \multicolumn{2}{|c|}{ PP1: I expressed my personal needs and opinion to the doctor/nurse } & 0.708 & 17.66 \\
\hline \multicolumn{2}{|c|}{ PP2: I shared and received information to manage my symptoms } & 0.745 & 20.61 \\
\hline \multicolumn{2}{|c|}{ PP3: I shared my feelings during the treatment/care planning } & 0.714 & 18.35 \\
\hline \multicolumn{2}{|c|}{ PP4: I had a high level of participation in the care process } & 0.826 & 29.38 \\
\hline \multicolumn{2}{|c|}{ PRV1: My participation helped me build a relationship with the doctor/nurse } & 0.824 & 30.00 \\
\hline \multicolumn{2}{|c|}{ PRV2: My participation made the interaction enjoyable } & 0.853 & 35.25 \\
\hline \multicolumn{2}{|c|}{ PRV3: My participation received approval from the doctor/Nurse } & 0.864 & 3759 \\
\hline \multicolumn{2}{|c|}{ PS1: This clinic/hospital is a good one to attend } & 0.701 & 18.90 \\
\hline \multicolumn{2}{|l|}{ PS2: I received the care I expected } & 0.738 & 22.83 \\
\hline \multicolumn{2}{|c|}{ PS3: I am satisfied with the care provided by doctor/nurse } & 0.991 & 15.20 \\
\hline \multicolumn{2}{|c|}{ PS4: Overall, I am satisfied with the service from the clinic/hospital } & 0.809 & 20.05 \\
\hline \multicolumn{2}{|c|}{ PAC1: My level of attachment to this hospital/clinic is high } & 0.763 & 20.60 \\
\hline \multicolumn{2}{|c|}{ PAC2:My commitment to my relationship with this hospital/clinic is high } & 0.834 & 27.24 \\
\hline \multicolumn{2}{|c|}{ PAC3: The level of friendship between the doctor/nurse and me is high } & 0.727 & 17.90 \\
\hline \multicolumn{2}{|c|}{ PAC4: My relationship with this hospital/clinic means a great deal to me } & 0.712 & 16.96 \\
\hline \multicolumn{2}{|c|}{ PL1: I will use this hospital/ clinic again as my provider } & 0.743 & 20.31 \\
\hline \multicolumn{2}{|c|}{ PL2: In the future, I will continue using this hospital/clinic as my provider } & 0.717 & 18.68 \\
\hline \multicolumn{2}{|c|}{ PL3: I will recommend this hospital/clinic to others } & 0.877 & 38.32 \\
\hline \multicolumn{2}{|c|}{ PL4: I will maintain the relationship with this hospital/clinic in the future } & 0.840 & 32.24 \\
\hline
\end{tabular}

Note. $\mathrm{CR}=$ composite reliability. AVE $=$ average variance extracted. ${ }^{\mathrm{a}}$ Indicates an acceptable level of reliability and convergent validity

Table 3. Correlations and discriminant validity for the measurement model

\begin{tabular}{|c|c|c|c|c|c|c|c|c|}
\hline Measure & Mean & $S D$ & PT & $\mathbf{P P}$ & PRV & PS & PAC & PL \\
\hline PT & 3.707 & 0.791 & 0.817 & & & & & \\
\hline PP & 3.394 & 0.911 & 0.624 & 0.749 & & & & \\
\hline PRV & 3.255 & 1.05 & 0.501 & 0.642 & 0.847 & & & \\
\hline PS & 3.630 & 0.798 & 0.642 & 0.592 & 0.493 & 0.817 & & \\
\hline PAC & 3.208 & 0.894 & 0.340 & 0.479 & 0.589 & 0.557 & 0.760 & \\
\hline PL & 3.472 & 0.875 & 0.494 & 0.513 & 0.448 & 0.616 & 0.644 & 0.796 \\
\hline
\end{tabular}

Note. For each construct, the square root of the average variance extracted (AVE) is represented in italics 
Table 4. The structural model

\begin{tabular}{lllll}
\hline Hypothesis & Path & Path coefficient & $\boldsymbol{t}$-value & Result \\
\hline$H 1$ & $\mathrm{PT} \rightarrow \mathrm{PP}$ & $0.63^{* * * *}$ & 6.49 & Supported \\
$H 2$ & $\mathrm{PP} \rightarrow \mathrm{PRV}$ & $0.93^{* * *}$ & 8.35 & Supported \\
$H 3$ & $\mathrm{PRV} \rightarrow \mathrm{PS}$ & $0.49^{* * *}$ & 8.34 & Supported \\
$H 4$ & $\mathrm{PRV} \rightarrow \mathrm{PAC}$ & 4.04 & Supported \\
$H 5$ & PS $\rightarrow$ PAC & $0.33^{* * * *}$ & 4.20 & Supported \\
$H 6$ & PS $\rightarrow$ PL & $0.30^{* * *}$ & 5.81 & Supported \\
$H 7$ & PAC $\rightarrow$ PL & $0.56^{* * *}$ & 3.25 & Supported \\
& Fit Indices & & & \\
& $\chi^{2}$ & & $671.16^{* * *}, d f=223$ & \\
& RMSEA & 0.070 & \\
& CFI & & 0.930 & \\
& TLI & & 0.950 & \\
& SRMR & & 0.023 & \\
\end{tabular}

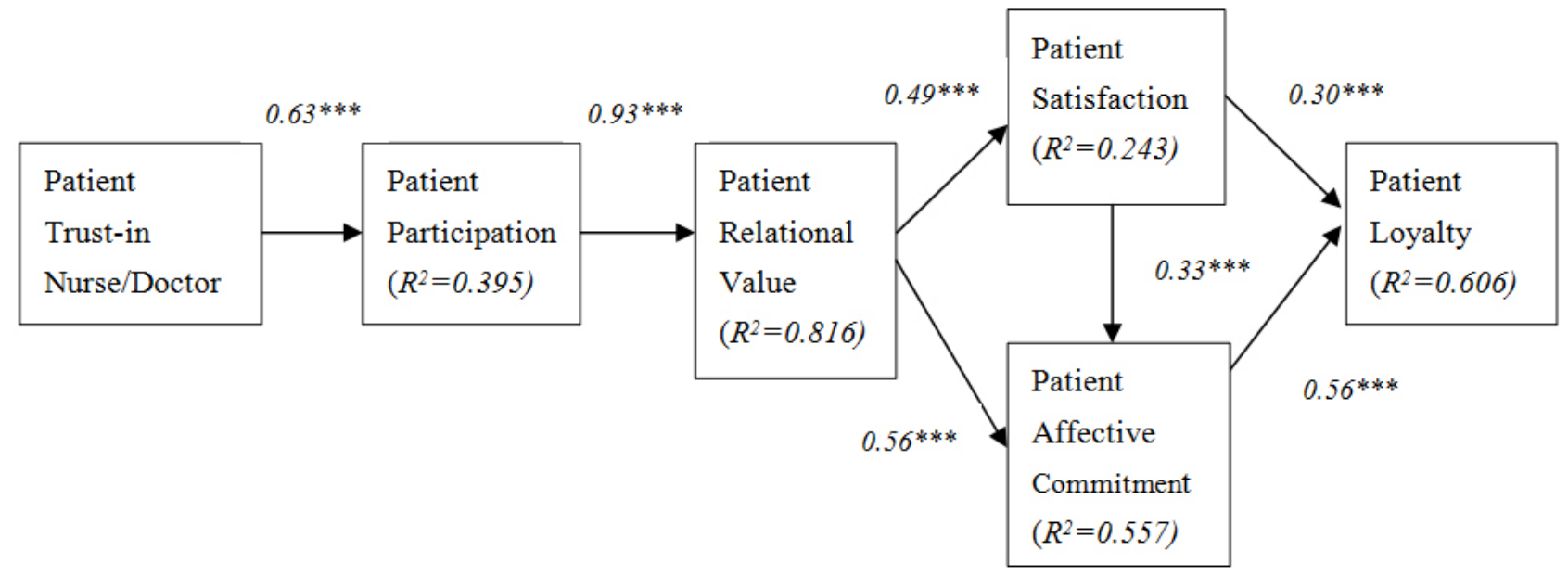

Figure 2. The research model

\section{Discussion}

The need to consider trust in customer participation and loyalty models, especially in healthcare settings, provided the impetus for this study. The paper makes contributions on two fronts. Firstly, the integrative model contributes to the service marketing literature by introducing trust-in personnel as a factor in the customer participation, satisfaction and loyalty model. Secondly, in the patient participation literature, the model illustrates the influential role of patient trust in a dyadic relationship with frontline service personnel-nurse and doctor, on patient participation, relational value, and loyalty. Previous studies have provided different pathways to value co-creation and loyalty. Previous work showed that customer participation directly affects relational value, and this subsequently influences satisfaction, and then repurchase intentions. ${ }^{[6]}$ While affective commitment was introduced into the model, it did not influence repurchase intentions. $\mathrm{Li}$ et al. showed that the trust-in personnel influences participation (co-delivery and value co-design behaviours), which subsequently affects customer perceived value, and then loyalty. ${ }^{[16]}$

The current model, however, shows that trust-in personnel influences participation, which affects patient relational value, and this impacts loyalty through both patient satisfaction and affective commitment. Thus, this study provides a better integrative model. The positive impact of affective commitment on loyalty also corroborates previous works, but some studies have reported that there is no such effect. ${ }^{[6]}$ The service context may contribute to such mixed results. In healthcare settings, this study suggests that how the patient 
feels about the health service and bonds psychologically with the provider is essential, and the bonding translates into a readiness to re-use or recommend the facility. Satisfaction also reinforces affective commitment.

\subsection{Managerial implications}

This study has shown that patient's trust-in doctor/nurse is a fundamental requirement for participation, and suggests the need for healthcare management teams to create the necessary conditions to build trust and promote participation. Health policies on patient participation and their implementation are vital, not only to health outcomes but also to service outcomes. The study shows the necessity for health organizations and policymakers to create policies and a culture that involve patients in value creation to enhance their healthcare experience. Indeed patients can participate in the creation of healthcare through different behaviours, mental attitudes and models of value creation. ${ }^{[4]}$ The current model emphasizes the realization of relationship value through trust and participation. Patients' role as strategic partners depends on their loyalty, but loyalty must be earned. The extent to which management works towards building trust and promoting participation will determine whether loyalty will ultimately ensue.

\subsection{Limitations}

The study did not differentiate trust-in facility from trust-in personnel, but the former is known to influence participation in some settings. ${ }^{[16]}$ Future research should explore the interaction between trust-in the facility and trust-in personnel on service participation, especially in medical settings where facilities-hospitals and clinics could determine the nature and level of trust. Repurchase or loyalty in medical settings could be affected by the ability to make choices, but this was not explored in the study. In settings where people are unable to select the medical facility of their choice due to finance, they are bound to re-use the same facility even if the services are not satisfactory. A comparison of models based on choices is worth examining. Both trust and participation are complex concepts to operationalize, especially in medical settings, and were simplified in this study. It might be worth testing the model using value co-creation, patient participation and citizenship behaviours, and in other service settings.

\section{CONFlicts OF InTEREST Disclosure}

The authors declare they have no conflicts of interest.

\section{REFERENCES}

[1] Kitson A, Marshall A, Bassett K, et al. What are the core elements of patient-centred care? A narrative review and synthesis of the literature from health policy, narrative review and synthesis of the literature from health policy, medicine and nursing. Journal of Advanced Nursing. 2013; 69(1): 4-15. PMid: 22709336. https://doi.org/10.1111/j.1365-2648.2012.06064 . x

[2] World Health Organization. Patients' rights. 2015. Available from: ht tp://www . who.int/genomics/public/patientrights/en/

[3] Tobiano G, Bucknall T, Marshall A, et al. Nurses' views of patient participation in nursing care. Journal of Advanced Nursing. 2015; 71(12): 2741-2752. PMid: 26216742. https ://doi .org/10.111 $1 /$ jan. 12740

[4] Mustak M, Jaakkola E, Halinen A. Customer participation and value creation: a systematic review and research implications. Managing Service Quality. 2013; 23(4): 341-359. https://doi.org/10.1 108/MSQ-03-2013-0046

[5] Chan KW, Yim CK, Lam SS. Is customer participation in value creation a double-edged sword? Evidence from professional financial services across cultures. Journal of Marketing. 2010; 74(3): 48-64. https://doi.org/10.1509/jmkg.74.3.048

[6] Cheng CV, Chen C. The role of customer participation for enhancing repurchase intention. Management Decision. 2017; 55(3): 547-562. https://doi.org/10.1108/MD-06-2016-0380

[7] Martovoy A, Santos JD. Co-creation and co-profiting in financial services. International Journal of Entrepreneurship and Innovation Management. 2012; 16(Nos 1/2): 114-135. https ://doi.org/10 .1504/IJEIM. 2012.050446
[8] Vargo SL, Lusch RF. Evolving to a new dominant logic for marketing. Journal of Marketing. 2004; 68(1): 1-17. https ://doi .org/10.1 $509 / \mathrm{jmkg} \cdot 68 \cdot 1 \cdot 1 \cdot 24036$

[9] Akaka MA, Vargo SL, Lusch RF. The complexity of context: A service ecosystems approach for international marketing. J.Mark. Res. 2013; 21: 1-20. https://doi.org/10.1509/jim.13.0032

[10] Carrubbo L, Brunni R, Cavacece Y, et al. A service system platforms to improve value co-creation: Insights for Translational Medicine. In Service Dominant Logic: Network and Systems Theory and Service Science: Integrating Three perspectives for a new service agenda. Gummesson, E., Merle, C., Polese, F., Editors, Giannini Editore: Napoli: Italy; 2015.

[11] Bendapudi N, Leone RP. Psychological implications of customer participation inco-production. Journal of Marketing. 2003; 67(1): 14-28. https://doi.org/10.1016/j.eswa.2011.06.041

[12] Dong B, Sivakumar Evans KR, Zou S. Effect of customer participation on service outcomes: the moderating role of participation readiness. Journal of Service Research, 2014; 18(2): 160-176. https://doi.org/10.1177/1094670514551727

[13] Johnson MO. The shifting landscape of health care: toward a model of health care empowerment. American Journal of Public Health 2011; 101: 265-270. PMid: 21164096. https ://doi .org/10. 210 5/AJPH. 2009.189829

[14] Xie B, Wang M, Feldman R, et al. Internet use frequency and patient-centered care: measuring patient preferences for participation using the health information wants questionnaire. Journal of Medical Internet Research. 2013; 15: e132. PMid: 23816979. https://doi.org/10.2196/jmir. 2615 
[15] Russo G, Tartaglione AM, Cavacece Y. Empowering patients to cocreate a sustainable healthcare value. Sustainability. 2019;11: 1-20. https://doi.org/10.3390/su11051315

[16] Li EL, Luk STK, Liu BS. Customer participation behaviour for value co-creation in high versus low-contact services: the roles of trust-in-personnel and trust-in brand. Proceedings of Global Marketing Conference. Hong Kong; 2016. 1552-1565 p. https : //doi.org/10.15444/GMC2016.11.02.02

[17] Sirdeshmukh D, Singh J, Sabol B. Consumer trust, value, and loyalty in relational exchange. Journal of Marketing. 2002; 66(3): 15-37. https://doi.org/10.1509/jmkg.66.1.15.18449

[18] Weingart SN, Zhu J, Chiappetta L, et al. Hospitalized patients' participation and its impact on quality of care and patient safety. International Journal for Quality in Health Care. 2011; 23(3): 269-277. PMid: 21307118. https://doi.org/10.1093/intqhe/mzr002

[19] Gallan AS, Jarvis CB, Brown SW, et al. Customer positivity and participation in services: an empirical test in a health care context. Journal of the Academy of Marketing Science. 2013; 41(3): 338-356. https ://doi.org/10.1007/s11747-012-0307-4

[20] Eldh AC, Luhr K, Ehnfors M. The development and initial validation of a clinical tool for patients' preferences on patient participation - the 4Ps. Health Expectations. 2014. PMid: 24938672. https://doi.org/10.1111/hex.12221

[21] Florin J, Ehrenberg A, Ehnfors M. Patient participation in clinical decision-making in nursing: a comparative study of nurses' and patients' perceptions. Journal of Clinical Nursing. 2006; 15: 14981508. PMid: 17118072 . https://doi.org/10.1111/j.1365-2 702.2005.01464.x

[22] Yim CK, Chan KW, Lam SSK. Do customers and employees enjoy service participation? Synergistic effects of self- and other-efficacy. Journal of Marketing. 2012; 76(6): 121-140. https://doi.org/ $10.1509 / j \mathrm{~m} .11 .0205$

[23] Hamilton M, Kaltcheva VD, Rohm AJ. Social media and value creation: the role of interaction satisfaction and interaction immersion. Journal of Interactive Marketing. 2016; 36: 121-133. https://doi.org/10.1016/j.intmar.2016.07.001

[24] Bayraktar E, Tatoglu E, Turkyilmaz A, et al. Measuring the efficiency of customer satisfaction and loyalty for mobile phone brands with DEA. Expert Systems with Applications. 2012; 39(1): 99-106. https://doi.org/10.1016/j.eswa.2011.06.041

[25] Fleming JH, Coffman C, Harter JK. Manage your human sigma. Harvard Business Review. 2005; 83(7/8): 106-114.

[26] Zhang L, Tong H, Demirel HO, et al. A practical model of value co-creation in healthcare service. Procedia Manufacturing. 2015; 3 : 200-207. https://doi .org/10.1016/j.promfg. 2015.07.129

[27] Kim SC, Kim S, Boren D. The quality of therapeutic alliance between patient and provider predicts general satisfaction. Mil. Med. 2008; 173: 85-90. PMid: 18251337. https://doi.org/10.7205/MILM ED. 173.1 .85

[28] Auh S, Bell SJ, McLeod CS, et al. Co-production and customer loyalty in financial services. Journal of Retailing. 2007; 83(3): 359-370. https://doi.org/10.1016/j.jretai.2007.03.001

[29] Patterson PG, Smith T. A cross-cultural study of switching barriers and propensity to stay with service providers. Journal of Retailing. 2003; 79(2): 107-120. https://doi.org/10.1016/S0022-435 9 (03) 00009-5

[30] Ekman I, Swedberg K, Taft C, et al. Person-centered care - ready for prime time. European Journal of Cardiovascular Nursing. 2011; 10:
248-251. PMid: 21764386. https://doi.org/10.1016/j.ejen urse.2011.06.008

[31] Lee CK, Kim HC, Lee S. The service quality dimensions and patient co-creation practice styles. J. Serv. Res. 2012; 12: 370-389.

[32] Ramani G, Kumar V. Interaction orientation and firm performance. Journal of Marketing. 2008; 72(1): 27-45. https ://doi .org/10 $.1509 / j m k g .72 .1 .027$

[33] Zhou Z, Fang Y, Vogel D, et al. Attracted to or locked in? Predicting continuance intention in social virtual world services. Journal of MIS 2012; 29 (1): 273-305. https ://doi .org/10. 2753/MIS0742-1 222290108

[34] Solem BAA. Influences of customer participation and customer brand engagement on brand loyalty. Journal of Consumer Marketing. 2016; 33(5): 332-342. https://doi .org/10.1108/JCM-04-201 5-1390

[35] Mittal V, Kamakura WA. Satisfaction, repurchase intent, and repurchase behavior: investigating the moderating effect of customer characteristics. Journal of Marketing Research. 2001; 38(1): 131-142. https://doi.org/10.1509/jmkr.38.1.131.18832

[36] Keiningham TL, Frennea CM, Aksoy L, et al. A five-component customer commitment model: implications for repurchase intentions in goods and services industries. Journal of Service Research. 2015; 18(4): 433-450. https://doi.org/10.1177/10946705155788 23

[37] Lam SY, Shankar V, Erramilli MK, et al. Customer value, satisfaction, loyalty, and switching costs: an illustration from a businessto-business service context. Journal of the Academy of Marketing Science. 2004; 32(3): 293-311. https://doi.org/10.1177/00 92070304263330

[38] Kline RB. Principles and practice of structural equation modeling. 3rd ed. Guilford Press: New York; 2011.

[39] Hair JF, Ringle CM, Sarstedt M. PLS-SEM: Indeed a silver bullet. J. Mark. Theory Pract. 2011; 19: 139-151. https ://doi .org/10.2 753/MTP1069-6679190202

[40] van Trijp SJ. Use of LISREL in validating marketing constructs. Int. J. Res. Mark. 1991; 8: 283-299. https://doi .org/10.1016/01 67-8116 (91) 90027-5

[41] Bagozzi RP, Yi Y. Specification, evaluation, and interpretation of structural equation models. J. Acad. Mark. Sci. 2012; 40: 8-34. https://doi .org/10.1007/s11747-011-0278-x

[42] Fornell C, Larcker DF. Evaluating structural equation models with unobservable variables and measurement error. J. Mark. Res. 1981; 18: 39-50. https://doi .org/10.1177/002224378101800104

[43] Diamantopoulos A, Siguaw JA. Introducing LISREL; Sage Publications: London, UK; 2000. PMid: 21764386. https ://doi .org/10 $.1016 / \mathrm{j}$. ejcnurse.2011.06.008

[44] MacCallum RC, Browne MW, Sugawara HM. Power analysis and determination of sample size for covariance structure modeling. Psychol. Methods. 1996; 1: 130. https://doi.org/10.1037//108 2-989X.1.2.130

[45] Awang Z. Structural Equation Modeling Using Amos Graphic; UiTM Press: Shah Alam, Malaysia; 2012.

[46] Hu LT, Bentler PM. Cutoff Criteria for Fit Indexes in Covariance Structure Analysis: Conventional Criteria. J. Mark. Theory Pract. 2008; 16: 287-298.

[47] McColl-Kennedy JR, Vargo SL, Dagger TS, et al. Health Care Customer Value Cocreation Practice Styles. J. Serv. Res. 2012; 12: 370389. https://doi.org/10.1177/1094670512442806 